\title{
Experimental Investigation of Interfacial Tension Measurement and Oil Recovery by Carbonated Water Injection: A Case Study Using Core Samples from an Iranian Carbonate Oil Reservoir
}

\author{
Bijan Honarvar, ${ }^{*}{ }^{\dagger}$ Amin Azdarpour, ${ }^{*}{ }^{\dagger} \odot$ Mohammad Karimi, ${ }^{\dagger}$ Ali Rahimi, ${ }^{\dagger}$ Mohammad Afkhami Karaei, ${ }^{\dagger}$ \\ Hossein Hamidi, James Ing, ${ }^{\ddagger}$ and Erfan Mohammadian ${ }^{\S}$ \\ ${ }^{\dagger}$ Department of Petroleum Engineering, Marvdasht Branch, Islamic Azad University, Marvdasht, Iran \\ ${ }^{\ddagger}$ School of Engineering, University of Aberdeen, Aberdeen AB24 3UE, Scotland, U.K. \\ ${ }^{\S}$ Faculty of Chemical Engineering, Universiti Teknologi MARA, Shah Alam, Selangor 40100, Malaysia
}

\begin{abstract}
Low volumetric sweep efficiency, early breakthrough of injected fluid, and high risk of gas leakage from the reservoir are the major technical challenges associated with direct gas and water injection into oil reservoirs. Injection of carbonated water $(\mathrm{CW})$ into oil reservoirs is a carbon dioxide-augmented water injection technique, which results in improved oil recovery and possible $\mathrm{CO}_{2}$ storage in the reservoir. In this paper, the potential of carbonated water injection (CWI) into an Iranian carbonate reservoir for the purpose of improving oil recovery was investigated. In addition, the interfacial tension (IFT) of crude oil and two different carbonated brines (carbonated formation brine and carbonated seawater) as well as $\mathrm{CO}_{2}$ solubility in these two carbonated brines was determined. Experimental results showed that $\mathrm{CO}_{2}$ solubility in both brines increases with pressure and decreases with temperature. However, $\mathrm{CO}_{2}$ solubility was more promising in seawater compared to formation brine because of the lower salinity. The IFT results showed that increasing the temperature from 40 to $100{ }^{\circ} \mathrm{C}$ and increasing the pressure from 1000 to 2500 psi had a positive impact on reducing the IFT between carbonated brines and oil. In addition, core flooding experiments showed that oil recovery increased with CWI as compared to conventional water flooding (WF). However, secondary carbonated water injection (SCWI) resulted in higher oil recovery compared to tertiary carbonated water injection (TCWI). A maximum oil recovery of $21.75 \%, 61.63 \%$, and $52.58 \%$ was achieved with conventional WF, SCWI, and TCWI, respectively.
\end{abstract}

\section{INTRODUCTION}

The demand for energy is increasing day by day, and fossil fuels as the main energy sources in the world play an important role in energy management scenarios. ${ }^{1-4}$ The days of easy oil are over, and the expense of drilling and exploration continues to increase. Thus, an emphasis has been placed on maximizing recovery of in place oil. Hence methods to enhance oil recovery (EOR) from oil reservoirs are becoming increasingly important. Gas injection into reservoirs is one of the most attractive EOR methods. Among different gases injected to the reservoir, $\mathrm{CO}_{2}$ has received the most attention. Due to its lower solubility pressure and higher solubility in brine it is the most widely injected EOR gas. ${ }^{5-11}$ This has the additional benefit of mitigating climate effects, which $\mathrm{CO}_{2}$ would otherwise produce. ${ }^{12-16} \mathrm{CO}_{2}$ injection into oil and gas reservoirs improve oil and gas recovery from these reservoirs as well as securing $\mathrm{CO}_{2}$ from the atmosphere, however the technical challenges still. $^{17-19}$

One of the critical challenges associated with any $\mathrm{CO}_{2}$ flooding is the high velocity of the injected $\mathrm{CO}_{2}$, which causes viscous fingering and poor sweep. ${ }^{18,19}$ In addition, because of high mobility of injected $\mathrm{CO}_{2}$ and the risk of $\mathrm{CO}_{2}$ leakage from the reservoir, the efficiency of $\mathrm{CO}_{2}$ sequestration could be affected. ${ }^{18,20-24}$ The use of water to reduce and control the mobility of injected gas has been proposed to improve the performance of gas injection; however, technical challenges are still present. The presence of water reduces the rate of $\mathrm{CO}_{2}$ mass transfer, oil swelling, and viscosity reduction and, thus, lowers the oil recovery. ${ }^{25-29}$

Interfacial tension (IFT) between oil and water plays an important role in controlling the amount of recovered oil. IFT reduction leads to an increase in capillary number $(\mathrm{Nc})$ by orders of magnitude, which enhances the oil recovery significantly. Conventional methods of IFT reduction involves the use of chemicals, most importantly surfactants and alkalis. However, other mechanisms including wettability alteration and emulsification also occurs in the presence of chemicals. $^{30-32}$ Carbonated water injection (CWI) has received significant attention recently for improving oil recovery. In this method, $\mathrm{CO}_{2}$ is dissolved in the water before injection and then injected to the reservoir. In this method, the adverse effect of water shielding to reduce the effectiveness of $\mathrm{CO}_{2}$ gas is minimized. Thus, oil mobility and sweep efficiency is significantly improved through CWI. Several mechanisms including oil viscosity reduction, IFT reduction, wettability alteration, oil swelling, and coalescence of the trapped oil ganglia are proposed for improving oil recovery through CWI. $^{33-42}$

Mosavat and Torabi ${ }^{43,44}$ studied the performance of CWI in a light oil system. Their experiments were conducted in an 
artificially unconsolidated sand-pack, and the effect of different operating conditions on the overall performance of CWI was investigated. Results of flooding experiments showed that ultimate recovery is higher when CW is injected as compared to conventional water injection. In their experiments, a maximum oil recovery of $78.76 \%$ was achieved, while a maximum oil recovery of $59.74 \%$ was achieved with conventional waterflooding. They also concluded that the process is efficient from a $\mathrm{CO}_{2}$ storage point of view since $40.7 \%-61.1 \%$ of the total injected $\mathrm{CO}_{2}$ was stored at the end of CWI. They stated that CWI provides a great potential to permanently store a significant portion of the injected $\mathrm{CO}_{2}$ in light oil reservoirs while improving oil recovery.

Alizadeh et al., ${ }^{45}$ investigated the effectiveness of CWI in both macro- and microscale flooding systems. They found out recovery factor is increased with CWI in both systems as compared to conventional waterfloods. In the microscale, the recovery factor increased from $35 \%$ to $75.4 \%$ with CWI. Similarly, in the macroscale core flooding experiments, the recovery factor increased from $40.1 \%$ to about $74.47 \%$ with CWI. In another study by Mosavat and Torabi, ${ }^{46}$ the wettability alteration and thus, improving oil recovery by CWI in a microscale system were explored. Their experiments showed that the wettability of micromodels changed from mixed and oil-wet to water-wet as the CWI proceeds. Their experiments showed that recovery factor is increased with CWI as compared to conventional waterflooding. However, the increase in recovery factor was $9.4 \%$ and $7.3 \%$ for secondary and tertiary scenarios, respectively.

Hasanvand et al. ${ }^{40}$ performed a case study in one of Iran's southern reservoirs. The performance of CWI was compared with natural depletion of the reservoir and conventional waterflooding. In addition, the effectiveness of the process for sequestering $\mathrm{CO}_{2}$ was also investigated. Their results showed that CWI could increase ultimate recovery by up to $20 \%$ compared to water injection and $71 \%$ compared to when the reservoir is naturally depleted. Moreover, nearly $75 \%$ of the injected $\mathrm{CO}_{2}$ was safely stored and sequestered. In another case study by Shakiba et al., ${ }^{42}$ the oil recovery and $\mathrm{CO}_{2}$ storage during secondary and tertiary injection of $\mathrm{CW}$ in an Iranian carbonate oil reservoir were investigated. They concluded that the recovery factor in both cases (secondary and tertiary CWI) was higher than for conventional waterflooding. However, oil recovery was higher when $\mathrm{CW}$ was applied as secondary recovery rather than tertiary recovery. The decrease in oil recovery with tertiary CWI was because the critical amount of oil remained in the system after the initial waterflood stage.

Sohrabi et al. ${ }^{47}$ investigated the effect of oil viscosity on the overall performance of CW injection. Three different oils with different viscosities including a light oil with the viscosity of $0.82 \mathrm{cP}$, a refined oil with the viscosity of $81 \mathrm{cP}$ and a stock tank crude oil with the viscosity of $145 \mathrm{cP}$ were used. Their experiments showed that oil recovery is indirectly related to oil viscosity where oil recovery was higher for lighter oil. They concluded that mobility ratio and oil swelling are the major mechanisms for increasing oil recovery with lighter oil. They found that mobility ratio was more favorable when lighter oil was used as compared to heavier oils. Apart from that, $\mathrm{CO}_{2}$ diffusion from carbonated water into the oil found to be important, which resulted in unlimited oil swelling and enhanced oil recovery. On the other hand, viscosity reduction is also one of the oil recovery mechanisms with $\mathrm{CW}$ injection. Viscosity reduction is more significant with heavier oils than the light oils. However, it seems that oil swelling and mobility ration are dominant over the oil viscosity reduction, which resulted in higher oil recovery with light oil than the heavy oil. This statement is also in good agreement with results of Mosavat and Torabi. ${ }^{43}$

In this study, the feasibility of CWI into core samples of a carbonated oil reservoir in Iran was investigated. Initially, $\mathrm{CO}_{2}$ solubility in formation brine and seawater under different pressures $(500-4000 \mathrm{psi})$ and temperatures $\left(25-100{ }^{\circ} \mathrm{C}\right)$ was investigated. Then, the effect of different pressure (1000-2500 psi) and temperatures $\left(40-100{ }^{\circ} \mathrm{C}\right.$ ) on IFT of crude oil and carbonated brine was investigated. After exploring the results of $\mathrm{CO}_{2}$ solubility and IFT, a series of coreflood experiments were designed and implemented. A carbonated core sample and crude oil from a carbonated oil reservoir in Iran were used for this purpose. Three main flooding scenarios including conventional WF, SCWI, and TCWI were designed and conducted at constant temperature and pressure of $80{ }^{\circ} \mathrm{C}$ and 1000 psi, respectively. Finally, oil recovery under each scenario was calculated and analyzed, respectively.

\section{EXPERIMENTAL SECTION}

2.1. Fluids. Crude oil in this study was taken from a carbonated oil reservoir in Iran. The physical and chemical properties of crude sample including density, viscosity, and composition analysis were measured and presented in Tables 1-3. As shown in Table 1, the API of crude

Table 1. SARA Analysis of Crude Oil Used in This Study

$\begin{array}{ccccc}\text { saturated (\%) } & \text { asphaltene (\%) } & \text { resin (\%) } & \text { aromatic (\%) } & \text { API } \\ 51.35 & 8.59 & 9.78 & 30.28 & 31.56\end{array}$

oil is 32.56. In addition, saturated, asphaltene, resin, and aromatic percentage is $51.35,8.59,9.78$ and $30.28 \%$, respectively. Table 2 represents the compositional analysis of crude oil used in this study. As shown in this table, the crude oil used in this study is rich in $\mathrm{C}_{1}$ (47.66\%) and $\mathrm{C}_{7+}(25.49 \%)$ with no presence of $\mathrm{CO}_{2}$ and $\mathrm{H}_{2} \mathrm{~S}$. Table 3 represents the density and viscosity of crude oil at different temperatures. As shown in this table, the viscosity of the crude oil is in the range of 0.848 to $0.883 \mathrm{~g} / \mathrm{cm}^{3}$. On the other hand, the measured crude oil viscosity is in the range of $4.62-24.94 \mathrm{cP}$.

Formation brine and seawater were used to represent brine in this study. The components and total dissolved solids (TDS) of both were determined as shown in Table 4. The TDS of formation brine was measured to be $97645 \mathrm{ppm}$, while the value was $35079 \mathrm{ppm}$ for seawater. In addition, the physical properties of formation brine including total hardness, conductivity, density, turbidity, and $\mathrm{pH}$ were measured, and the results are shown in Table 5.

Analytical grade $\mathrm{CO}_{2}$ (purity $>99.9 \%$ ) was used to prepare the CW sample. In order to differentiate between different liquid phases in flooding tests, blue and red dyes were used for brine and oil, respectively.

2.2. Core Samples. The core samples used in this study were taken from outcrops of an Iranian carbonate oil reservoir. Porosity of the core samples were measured using helium porosity test and brine was used to determine the permeability of the cores. Also, the dimensions of core samples were measured accordingly. Table 6 represents the dimensions and properties of carbonate core samples used in this study. The average porosity and permeability of core samples are $11.28 \%$ and $14.91 \mathrm{mD}$, respectively.

2.3. Apparatus. The experimental setup presented by Mohammadian et al. ${ }^{48}$ was used to measure $\mathrm{CO}_{2}$ solubility in brine under different pressures and temperatures. The solubility measurement setup consists of an ISCO pump (Teledyne, $100 \mathrm{DX}$ ), a $100 \mathrm{~mL}$ autoclave reactor equipped with a stirrer, $\mathrm{CO}_{2}$ cylinder, an electric heater, and a $1 / 8 \mathrm{in}$. dip tube, which was connected to a floating piston sampler fabricated locally. The sampler was controlled by a syringe 
Table 2. Compositional Analysis of Crude Oil Used in This Study

\begin{tabular}{|c|c|c|c|c|}
\hline Component & $\mathrm{C}_{1}$ & $\mathrm{C}_{2}$ & $\mathrm{C}_{3}$ & $i-\mathrm{C}_{4}$ \\
\hline mole $\%$ & 47.66 & 11.32 & 6.48 & 1.08 \\
\hline \multicolumn{5}{|c|}{$\begin{array}{l}\text { Table 3. Density and Viscosity of Crude Oil Used in Thi } \\
\text { Study }\end{array}$} \\
\hline \multicolumn{2}{|c|}{ temperature $\left({ }^{\circ} \mathrm{C}\right)$} & density $\left(\mathrm{g} / \mathrm{cm}^{3}\right)$ & & viscosity $(\mathrm{cP})$ \\
\hline \multicolumn{2}{|c|}{20} & 0.883 & & 24.94 \\
\hline \multicolumn{2}{|c|}{40} & 0.871 & & 12.14 \\
\hline \multicolumn{2}{|l|}{60} & 0.858 & & 7.04 \\
\hline \multicolumn{2}{|c|}{80} & 0.848 & & 4.62 \\
\hline
\end{tabular}

Table 4. Composition of Brines Used in This Study

\begin{tabular}{|c|c|c|}
\hline & seawater & formation brine \\
\hline ion & concentration (ppm) & concentration (ppm) \\
\hline $\mathrm{Ca}^{2+}$ & 419 & 3800 \\
\hline $\mathrm{Mg}^{2+}$ & 1304 & 1944 \\
\hline $\mathrm{Na}^{+}$ & 11100 & 38406 \\
\hline $\mathrm{HCO}_{3}^{-}$ & 146 & 45 \\
\hline $\mathrm{SO}_{4}{ }^{2-}$ & 2690 & 1200 \\
\hline $\mathrm{Cl}^{-}$ & 19350 & 52250 \\
\hline $\mathrm{Br}^{-}$ & 70 & 0 \\
\hline TDS & 35079 & 97645 \\
\hline
\end{tabular}

Table 5. Physical Properties of Formation Brine from a Carbonate Oil Reservoir in Iran

\begin{tabular}{ll}
\multicolumn{1}{c}{ properties } & \multicolumn{1}{c}{ value } \\
conductivity $(\mu \mathrm{s} / \mathrm{cm})$ & 184100 \\
total hardness $(\mathrm{mg} / \mathrm{L})$ & 17500 \\
density at $20^{\circ} \mathrm{C}\left(\mathrm{g} / \mathrm{cm}^{3}\right)$ & 1.1005 \\
turbidity $(\mathrm{NTU})$ & 0.40 \\
$\mathrm{pH}$ & 7.01
\end{tabular}

Table 6. Dimensions and Properties of the Reservoir Core Used in the Study

\begin{tabular}{cccccc}
$\begin{array}{c}\text { length } \\
(\mathrm{cm})\end{array}$ & $\begin{array}{c}\text { diameter } \\
(\mathrm{cm})\end{array}$ & $\begin{array}{c}\text { bulk volume } \\
\left(\mathrm{cm}^{3}\right)\end{array}$ & $\begin{array}{c}\text { pore volume } \\
\left(\mathrm{cm}^{3}\right)\end{array}$ & $\begin{array}{c}\text { porosity } \\
(\%)\end{array}$ & $\begin{array}{c}\text { permeability } \\
(\mathrm{mD})\end{array}$ \\
8.14 & 3.78 & 91.35 & 10.30 & 11.28 & 14.91 \\
\hline
\end{tabular}

pump manufactured by $K_{\mathrm{d}}$ scientific (model 53100). The dynamic IFT of different oil and water samples was measured using pendant drop method, as this method is one of the best methods for determining the IFT at reservoir conditions. In this study, IFT400 with a maximum operating pressure of $3000 \mathrm{psi}$ and temperature of $400^{\circ} \mathrm{F}$ was used to determine the IFT. The system has a $50 \mathrm{~cm}^{3}$ stainless steel chamber along with a glass window, which allows for taking photographs of the drops. Eventually, IFT was measured using an image processing code written by LabVIEW. In this method, the dynamic IFT is determined using drop shape analysis, commonly known as axisymmetric drop shape analysis (ADSA) technique. Figure 1 represents the schematic diagram of the IFT400 used in this study.

Figure 2 represents the schematic diagram of the coreflood setup used in this study. The coreflood setup consists of three fluid accumulators containing brine, $\mathrm{CW}$, and oil. The core was loaded in a high pressure stainless steel core holder. A syringe pump (ISCO 500D) with flow rates of up to $200 \mathrm{~mL} / \mathrm{min}$ and operating pressure of up to 3750 psi was used to inject fluids into the core samples. A backpressure regulator was installed at the outlet to allow for high pressure experiments. A calibrated cylinder was used to collect the produced liquids while a gasometer was used to record the produced

\begin{tabular}{ccccccc}
$n-\mathrm{C}_{4}$ & $i-\mathrm{C}_{5}$ & $n-\mathrm{C}_{5}$ & $\mathrm{C}_{6}$ & $\mathrm{C}_{7+}$ & $\mathrm{H}_{2} \mathrm{~S}$ & $\mathrm{CO}_{2}$ \\
2.89 & 1.21 & 1.49 & 2.38 & 25.49 & 0 & 0 \\
\hline
\end{tabular}

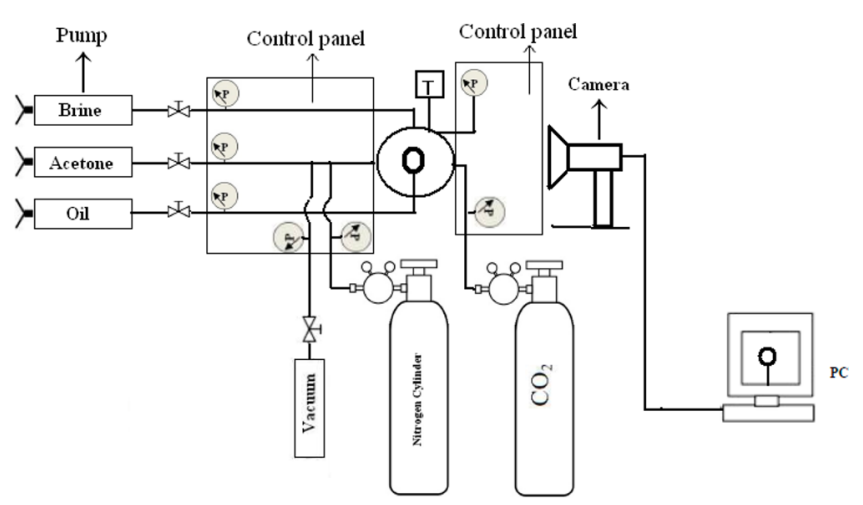

Figure 1. Schematic diagram of IFT400.

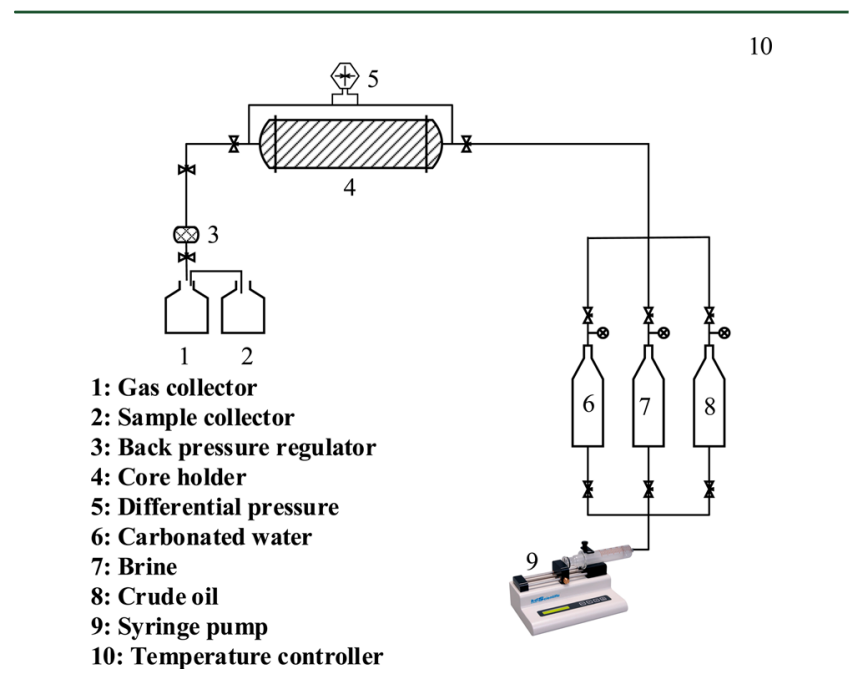

Figure 2. Schematic diagram of core flooding setup used in this study.

gas. All experiments were conducted at constant temperatures using an air bath system.

2.4. Experimental Procedure. $\mathrm{CO}_{2}$ solubility in formation brine and seawater was determined using the method explained by Mohammadian et al. ${ }^{48}$ In this method, brine is injected into the reactor and then heated to the desired temperature. $\mathrm{CO}_{2}$ is injected to the reactor at the desired pressure and then the equilibrium is achieved by stirring the solution between 3 and $24 \mathrm{~h}$. After that, a sample of $\mathrm{CO}_{2}$ saturated brine (half of chamber size) was taken and poured into the sampling chamber to react with $\mathrm{NaOH}$. This is to dissolve all carbon species in $\mathrm{NaOH}$ and convert them to $\mathrm{CO}_{3}{ }^{2-}$. The other half of sampling chamber was filled with distilled brine, which was gradually withdrawn (using a syringe pump) to allow the $\mathrm{CO}_{2}$ saturated brine reacting with the $\mathrm{NaOH}$. The reaction of $\mathrm{NaOH}$ and solution was given $30 \mathrm{~min}$ time before withdrawal. Then $\mathrm{HCl}$ was used to analyze the preserved $\mathrm{NaOH}$ samples using potentiometric method. $\mathrm{HCl}$ addition to analyte $\left(\mathrm{NaOH}\right.$ and $\mathrm{CO}_{3}{ }^{2-}$ mixture) was continued until the equivalence point was achieved. Finally, $\mathrm{CO}_{2}$ solubility in brine was calculated in molar units $(\mathrm{mol} / \mathrm{kg})$.

The procedure given by Shu et al., ${ }^{49}$ was followed for preparing the carbonated water. A syringe pump and a high pressure transfer vessel (made of stainless steel) were utilized to prepare the carbonated water. Initially, the transfer vessel was filled with brine (either formation brine or seawater). The vessel was connected to the syringe pump under the pressure setting of 2000 psi. Then, the transfer vessel was placed in an air bath of room temperature and rocked for $24 \mathrm{~h}$ to achieve complete 
phase equilibrium between $\mathrm{CO}_{2}$ and brine. Finally, the prepared carbonated water was utilized for IFT measurements and flooding experiments.

In order to measure the IFT, initially the whole system was checked for leakage with deionized water. Then, it was cleaned with acetone and deionized water, flushed with nitrogen, and finally evacuated. To determine the IFT of carbonated water and crude oil, a total of $15 \mathrm{~cm}^{3}$ of brine (either formation brine or seawater) was injected to the high pressure cell. Then, $\mathrm{CO}_{2}$ was slowly injected to the cell to provide the desired pressure. Then, adequate time $(10-12 \mathrm{~h})$ was given to each solution to reach equilibrium conditions. An upward oil drop was introduced from the bottom of the cell by installing the syringe needle at the bottom of the pressure cell. In order to confirm the reproducibility of IFT data, the measurements were repeated three times and, then, the average was taken and reported.

In order to perform the flooding experiments, the core sample was dried and weighed. Then, the core was washed by injecting toluene, methanol, and formation brine. The brine permeability was determined using the recorded pressure data in this step. The core was dried again and evacuated by a vacuum pump. In the next step, the core was flooded with the formation brine until complete saturation with water was achieved. After this, the core was flooded with oil until an irreducible water saturation was achieved. After this step, three main experiments including water flooding (WF), secondary carbonated water injection (SCWI), and tertiary carbonated water injection (TCWI) were designed and implemented. For conventional water flooding, the maximum of three pore volumes (PV) of formation brine was injected into the core after establishing the irreducible water saturation. Three PV were chosen to make sure that all the recoverable oil is produced under conventional WF. For the TCWI, after establishing the irreducible water saturation, the first WF was performed using formation brine. Then, $\mathrm{CW}$ with the maximum of 5 PV was injected into the core sample. For the SCWI, 5 PV of CW was injected after establishing the irreducible water saturation. At the end, an oil recovery factor of WF, SCWI, and TCWI was calculated. All these flooding experiments were carried out at $1000 \mathrm{psi}$ and $80^{\circ} \mathrm{C}$. A constant displacement rate of $0.1 \mathrm{~cm}^{3} / \mathrm{min}$ was used in all flooding experiments in this study.

\section{RESULTS AND DISCUSSION}

3.1. $\mathrm{CO}_{2}-$ Brine Solubility. In this study, $\mathrm{CO}_{2}$ solubility in formation brine and seawater was determined at different pressures and temperatures. Figure 3 presents the solubility of $\mathrm{CO}_{2}$ in formation brine and seawater with respect to pressure changes at constant temperature of $80{ }^{\circ} \mathrm{C}$. Also, Figure 4 presents the effect of temperature on $\mathrm{CO}_{2}$ solubility at constant pressure of 1000 psi.

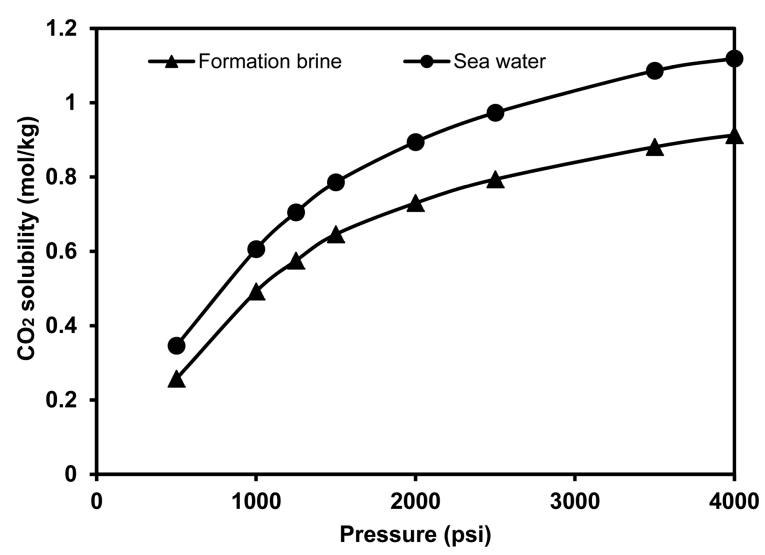

Figure 3. $\mathrm{CO}_{2}$ solubility in formation brine and seawater at $80{ }^{\circ} \mathrm{C}$ versus pressure.

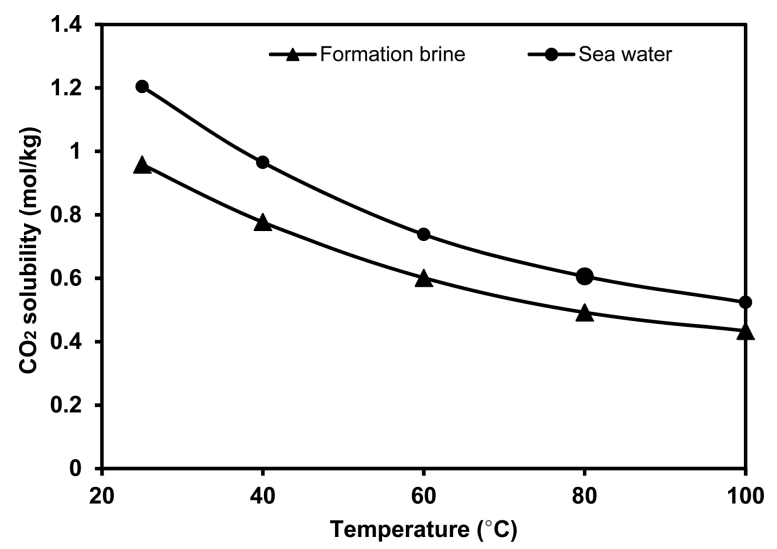

Figure 4. $\mathrm{CO}_{2}$ solubility in formation brine and seawater at $1000 \mathrm{psi}$ versus temperature.

As shown in Figure 3, $\mathrm{CO}_{2}$ solubility in brine increases with pressure regardless of the brine type. For both solutions, the minimum $\mathrm{CO}_{2}$ solubility is achieved at the lowest pressure $(500$ $\mathrm{psi}$ ) and the maximum value is achieved at the highest pressure (4000 psi). However, $\mathrm{CO}_{2}$ solubility becomes less sensitive to pressure at higher pressures (for example at pressures above $2500 \mathrm{psi}$ ). This could be because the highest $\mathrm{CO}_{2}$ saturation of brine is achieved at higher pressures. The increase in $\mathrm{CO}_{2}$ solubility can be explained by Henry's law as stated by Duan and Sun. ${ }^{50}$ Another observation from this figure is that $\mathrm{CO}_{2}$ solubility in seawater is always higher than $\mathrm{CO}_{2}$ solubility in formation brine, regardless of the pressure. At constant pressure and temperature, $\mathrm{CO}_{2}$ solubility is affected by brine salinity in which the higher the salinity, the lower the solubility. In this study, salinity of the formation brine is higher than the salinity of the seawater, thus a lower $\mathrm{CO}_{2}$ solubility is expected in formation brine rather than the seawater. This can be explained by a salting out effect where some fraction of water becomes unavailable for the $\mathrm{CO}_{2}$ when the salt ions are dissolved. Thus, $\mathrm{CO}_{2}$ solubility is reduced by increasing the brine salinity. ${ }^{48,51}$

On the other hand, increasing temperature decreases $\mathrm{CO}_{2}$ solubility in the formation brine and seawater, as shown in Figure 4. In addition, $\mathrm{CO}_{2}$ solubility is always higher in seawater as compared to formation brine, which is due to lower salinity of seawater. The kinetic energy is increased by increasing the temperature, and this results in more rapid motion between the molecules and, hence, breakage of intermolecular bonds. This enables molecules to escape to the gas phase. ${ }^{48,52,53}$ Thus, $\mathrm{CO}_{2}$ solubility is reduced by increasing the temperature regardless of the brine's salinity and pressure as the results presented here confirm.

3.2. Effect of $\mathrm{CO}_{2}$ on IFT. The effect of $\mathrm{CO}_{2}$ on IFT was determined by measuring the IFT of carbonated brines and oil. Formation brine and seawater were used to prepare $\mathrm{CW}$ and then IFTs were measured at $178{ }^{\circ} \mathrm{F}$ and $1000 \mathrm{psi}$ and at equilibrium state. Table 7 presents the results of IFTs of

Table 7. Equilibrium IFT of Carbonated Brine and Normal Brine with Oil

\begin{tabular}{lc}
\multicolumn{1}{c}{ solution } & IFT $(\mathrm{mN} / \mathrm{m})$ \\
formation brine/oil & 22.54 \\
seawater/oil & 17.12 \\
carbonated formation brine/oil & 15.18 \\
carbonated seawater/oil & 12.72
\end{tabular}


carbonated and normal brines with oil. The presence of $\mathrm{CO}_{2}$ in brine was found to be promising in reducing the IFT of oil and water, where carbonated brines (both formation brine and seawater) had lower IFTs as compared to normal brines. The IFT of formation brine/oil was $22.54 \mathrm{mN} / \mathrm{m}$, while the value was reduced to $15.18 \mathrm{mN} / \mathrm{m}$ for carbonated formation brine and oil. On the other hand, the IFT of seawater and oil was $17.12 \mathrm{mN} / \mathrm{m}$ and the value was reduced to $12.72 \mathrm{mN} / \mathrm{m}$ for carbonated seawater and oil.

$\mathrm{CO}_{2}$ solubility is a governing mechanism in controlling the IFT of carbonated brine and oil. At constant pressure and temperature, $\mathrm{CO}_{2}$ solubility is affected by brine salinity in which the higher the salinity the lower the solubility. ${ }^{48,50,52}$ In this study, the salinity of seawater is lower than the salinity of formation brine. Thus, it is expected to have a higher IFT with formation brine solutions as compared to seawater solutions as it happened in this study. Riazi and Golkari ${ }^{54}$ determined the IFT of carbonated and noncarbonated brine with oil. Their investigation showed that IFT of carbonated brine and oil is lower than the IFT of noncarbonated brine and oil. This is because $\mathrm{CO}_{2}$ dissolves in both brine and oil, which leads to IFT reduction. In addition, in the absence of $\mathrm{CO}_{2}$, water molecules are oriented across the surface via strong hydrogen bonds, forming a strong interface between water and oil. However, in the presence of $\mathrm{CO}_{2}$, due to low reactivity toward polar water molecules, they tend to move toward the surface (oil/water interface). As $\mathrm{CO}_{2}$ molecules reach the surface, they reduce the space available for water molecules, imposing some spatial (conformational) constraints onto water molecules. In response, hydrogen bonds among water molecules are weakened, which results in IFT reduction. Thus, IFT of carbonated brine and oil is lower than the IFT of brine and oil. $^{55}$

Another observation from drop analysis is the shape and volume of analyzed oil drops. Figure 5 represents typical images of the pendant drops of different solutions. Figure 5a represents
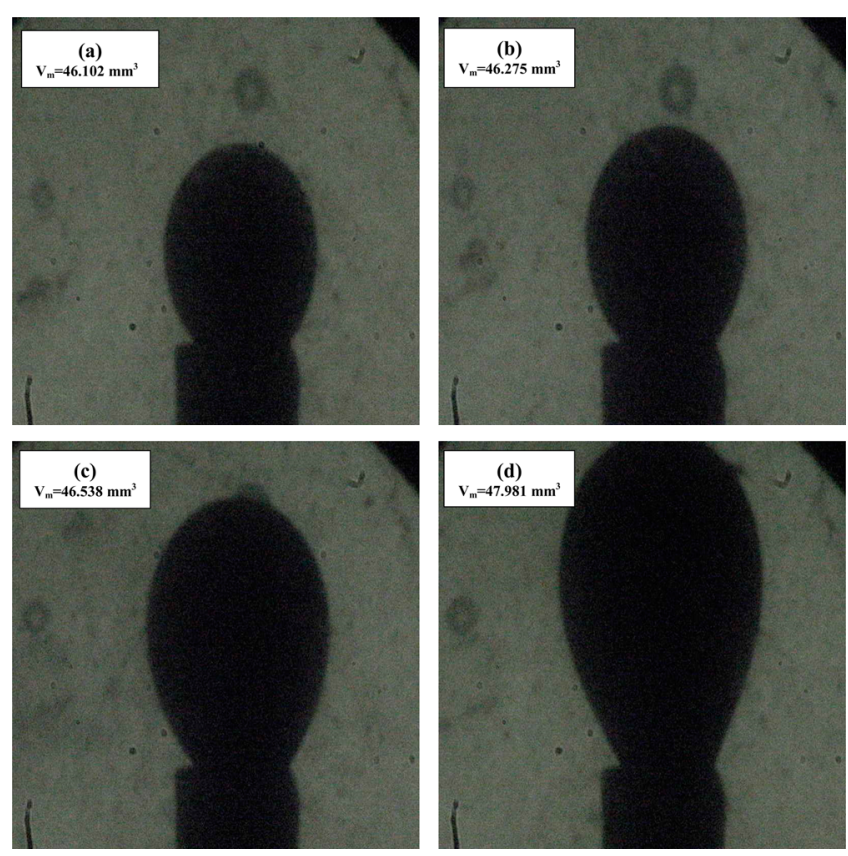

Figure 5. Digital images of pendant drops of (a) formation brine and oil drop; (b) carbonated formation brine and oil drop; (c) seawater and oil drop; (d) carbonated seawater and oil drop. oil drop in the presence of formation brine, b represents oil drop with carbonated formation brine, $c$ represents oil drop with seawater, and d represents oil drop with carbonated seawater. The increase in shape and volumes are clearly shown in these images, which is because of IFT reduction and oil swelling. This oil swelling is the result of dissolved $\mathrm{CO}_{2}$ in the $\mathrm{CW}$ phase and it partitioning at the $\mathrm{CW}$ and oil interface and subsequently its diffusion and dissolution into the oil phase. ${ }^{55,56}$

3.3. Effect of Temperature on the Carbonated Brine/ Oil IFT. The dynamic IFT of CFW/oil and CSW/oil systems was determined at different temperatures $\left(40-100{ }^{\circ} \mathrm{C}\right)$, and the results are shown in Figures 6 and 7, respectively. As shown

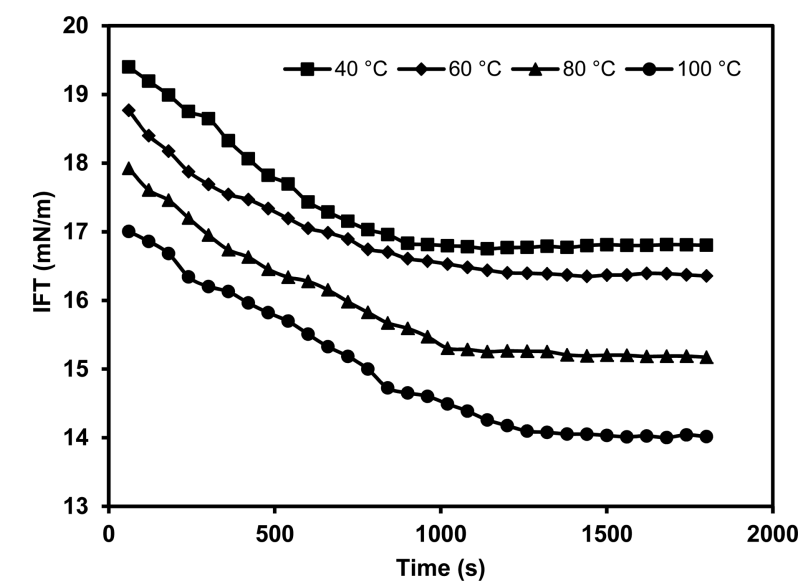

Figure 6. Dynamic IFT of CFW and oil versus temperatures.

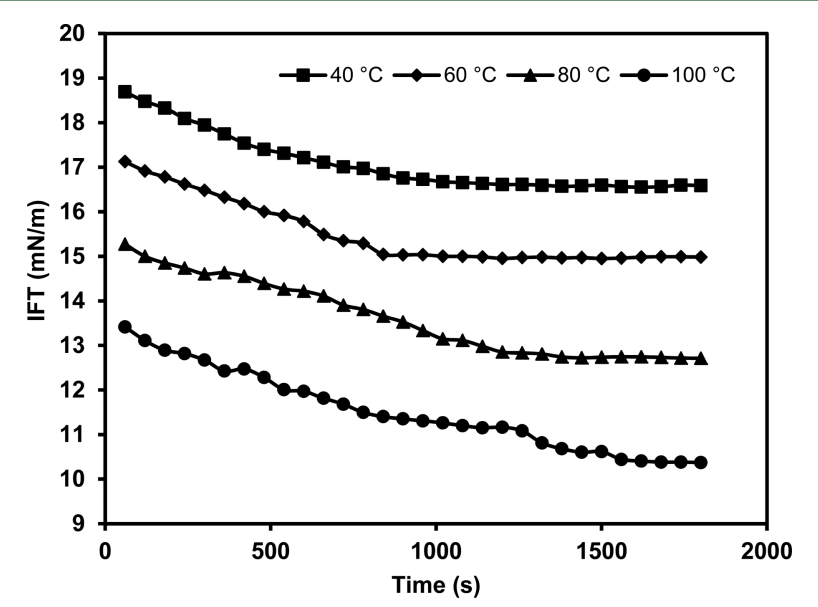

Figure 7. Dynamic IFT of CSW and oil versus temperatures.

in these figures, the dynamic IFT is decreased with temperature, regardless of brine type. The minimum value of IFT is achieved at $100{ }^{\circ} \mathrm{C}$, and the maximum value is achieved at 40 ${ }^{\circ} \mathrm{C}$. The CFW/oil IFT decreased from 16.80 to $14.02 \mathrm{mN} / \mathrm{m}$ by increasing the temperature from 40 to $100{ }^{\circ} \mathrm{C}$. On the other hand, the dynamic IFT of CSW/oil decreased from 16.59 to $10.37 \mathrm{mN} / \mathrm{m}$ by increasing the temperature to $100{ }^{\circ} \mathrm{C}$.

The IFT is affected by $\mathrm{CO}_{2}$ solubility in which the higher the solubility, the lower the IFT. An example is IFT reduction with increasing the pressure where $\mathrm{CO}_{2}$ solubility is increased, thus IFT is reduced. However, another mechanism that controls the IFT is the total entropy of the two phase surface. When it comes to temperature impact on IFT, the dominant mechanism is entropy change rather than the $\mathrm{CO}_{2}$ solubility. The kinetic 
energy and mobility of the molecules are increased with temperature, which inherently increases the total entropy of two phase surface and consequently, reduces the free energy $(\Delta G)$, resulting in lower IFT with temperature. ${ }^{54,57,58}$

Another observation from the IFT data was that the minimum value of IFT for CSW/oil was lower than the IFT of CFW/oil. As was explained earlier, at constant temperature and pressure, IFT is affected by the brine salinity. The higher the brine salinity, the lower the $\mathrm{CO}_{2}$ solubility and consequently the higher the IFT. ${ }^{48,50,52}$ The total salinity of the formation brine is higher than the salinity of the seawater, thus it is expected to have a lower IFT with solutions made by seawater, as confirmed in this study. The minimum value of IFT CFW/oil was $14.02 \mathrm{mN} / \mathrm{m}$ while it was $10.37 \mathrm{mN} / \mathrm{m}$ for CSW/oil.

3.4. Effect of Pressure on the Carbonated Brine/Oil IFT. The dynamic IFT of CFW/oil and CSW/oil was determined with respect to pressure changes from 1000 to 2500 psi as shown in Figures 8 and 9, respectively. Increasing

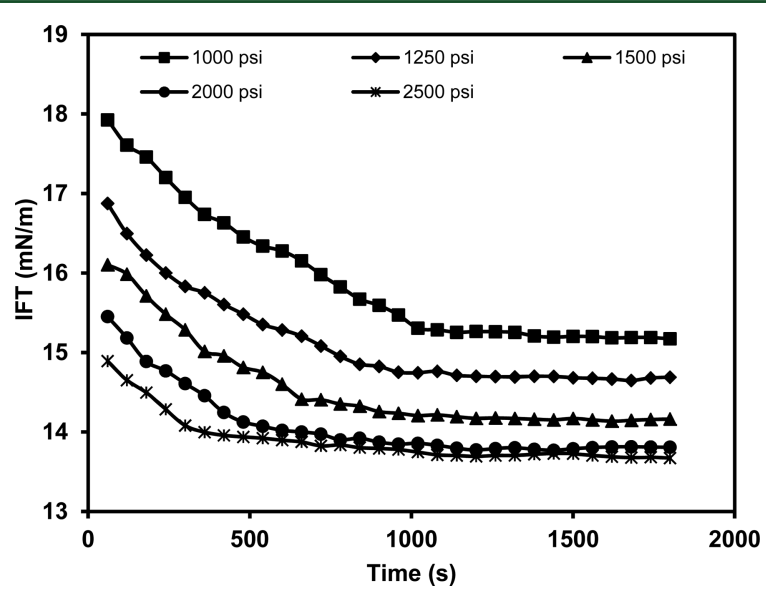

Figure 8. Dynamic IFT of CFW and oil versus pressure.

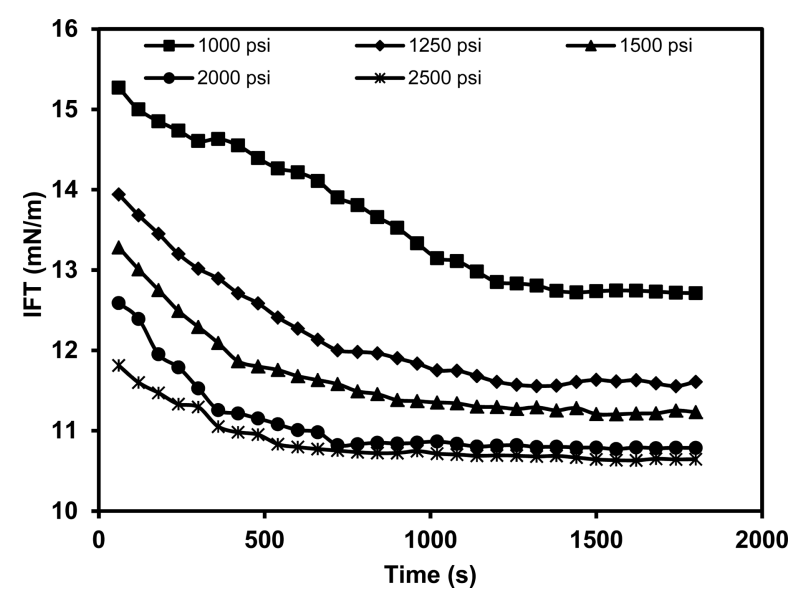

Figure 9. Dynamic IFT of CSW and oil versus pressure.

pressure was found to be favorable in reducing the IFT in which the minimum value of IFT was achieved under 2500 psi and the maximum value of IFT was achieved under 1000 psi. This trend was true for both CFW/oil and CSW/oil. However, the IFT of CSW/oil was lower than the IFT of CFW/oil. The IFT of CFW/oil reduced 15.17 to $13.67 \mathrm{mN} / \mathrm{m}$ by increasing the pressure from 1000 to 2500 psi. On the other hand, the IFT of CSW/oil reduced from 12.71 to $10.64 \mathrm{mN} / \mathrm{m}$ by increasing the pressure to 2500 psi.

As it was explained earlier, at constant temperature, pressure, and brine salinity are the governing factors in controlling the IFT. Increasing pressure enhances the solubility of $\mathrm{CO}_{2}$, which creates a favorable condition for reducing the IFT. Again, this was confirmed in the current study. Riazi and Golakri ${ }^{54}$ determined the IFT of carbonated brine and oil under variable pressure. Their results showed that the IFT is reduced by increasing the pressure from 2.76 to $13.79 \mathrm{MPa}$. They concluded that the IFT is affected by the solubility of $\mathrm{CO}_{2}$ in which the higher pressure is more favorable in reducing the IFT. Another observation from experimental results in this study was the effect of brine salinity on the IFT, which was explained earlier. Under 2500 psi, the IFT of CFW/oil was $13.67 \mathrm{mN} / \mathrm{m}$ while the value reduced to $10.64 \mathrm{mN} / \mathrm{m}$ for CSW and oil.

3.5. Effect of Aging Time on the Carbonated Brine/Oil IFT. As shown in Figures 6-9, the IFT of oil and carbonated brines (both carbonated formation brine and carbonated seawater) decreases with time, regardless of pressure and temperature. As shown in these figures, IFT decreased with time initially, followed by a relatively constant trend where it was at equilibrium state. No significant changes occurred in IFT after the equilibrium point was achieved. An observation based on these figures is that the pressure had stronger effect on equilibrium IFT compared to temperature. In other words, IFT reduced with a slower rate with temperature as compared to pressure. This is because the equilibrium IFT was achieved faster when different pressures were used as compared to the experiments where different temperatures were used. The equilibrium IFT was achieved after 840-1560 s when different temperatures were applied while the value was found to be 360-1020 s when different pressures were applied.

$\mathrm{CO}_{2}$ absorption along carbonated water and oil interface is promoted with time. In addition, $\mathrm{CO}_{2}$ tends to leave the water phase and move into the oil phase, which results in IFT reduction. However, beyond a certain time (equilibrium point), the same amount of $\mathrm{CO}_{2}$ absorbed along the interface is transferred into the oil phase, maintaining a relatively constant IFT. Meanwhile, increasing the temperature increases the molecular movements, causing $\mathrm{CO}_{2}$ molecules to exhibit further affinity toward leaving the water phase and move toward the oil phase. Thus, postponing the time by which IFT reaches an equilibrium state, i.e., IFT reduces at a slower rate. On the other hand, IFT reduction with pressure experienced a faster rate. As was explained earlier, as little as $360 \mathrm{~s}$ was required for the IFT to reach equilibrium under 2500 psi. The reason for this phenomenon is that $\mathrm{CO}_{2}$ solubility is greatly increased at higher pressure, which promotes IFT reduction. In other words, the reason for fast convergence of IFT to equilibrium state at higher pressures is the rapid saturation of $\mathrm{CO}_{2}$ along the interface, which results in achieving the equilibrium state at a faster rate. ${ }^{56,62}$

3.6. Oil Recovery. In order to investigate the effect of CW on oil recovery, conventional WF and SCWI were implemented at $80^{\circ} \mathrm{C}$ and 1000 psi. Figure 10 represents the oil recovery of both conventional WF and SCWI in terms of injected PV.

As shown in this figure, oil recovery increased with increasing injected PV for both conventional WF and SCWI. However, $\mathrm{CW}$ was shown to be more efficient than conventional WF. Oil recovery of conventional WF gradually increases from its lowest value of $8.41 \%$ under $0.1 \mathrm{PV}$ of injected brine to its maximum 


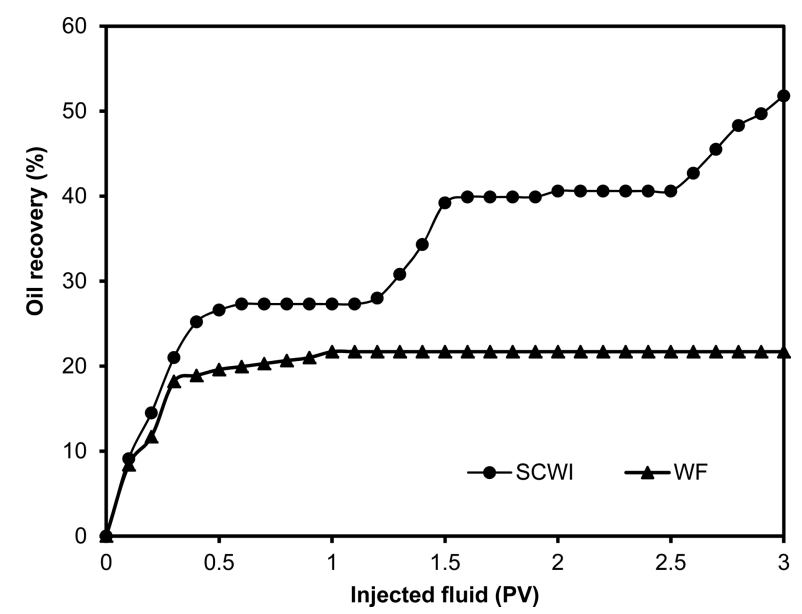

Figure 10. Oil recovery of conventional WF and SCWI.

value of $21.75 \%$ under $1 \mathrm{PV}$ of injected brine. The oil recovery remained unchanged with further increasing the injected brine to about $3 \mathrm{PV}$ as can be seen from Figure 10. On the other hand, oil recovery with $\mathrm{CW}$ revealed a slightly different behavior. Oil recovery increment found to be stage wise with CW injection. Initially, oil recovery increased from $9.11 \%$ (under $0.1 \mathrm{PV}$ ) to about 27.38\% (under $0.6 \mathrm{PV}$ ) and then it remained almost unchanged with further increasing the PV to about 1.1 PV. In the next step, oil recovery again started to increase to about $39.26 \%$ (under $1.5 \mathrm{PV}$ ) and then remained almost unchanged with further increasing the PV to about 2.5 PV. In the final step, oil recovery again increased to about $51.84 \%$ under $3 \mathrm{PV}$ of injected CW. In general, it seems that oil recovery is more favorable with $\mathrm{CW}$ injection as compared to conventional WF.

The efficiency of SCWI and TCWI was compared and the results are shown in Figure 11. TCWI with the maximum of 5

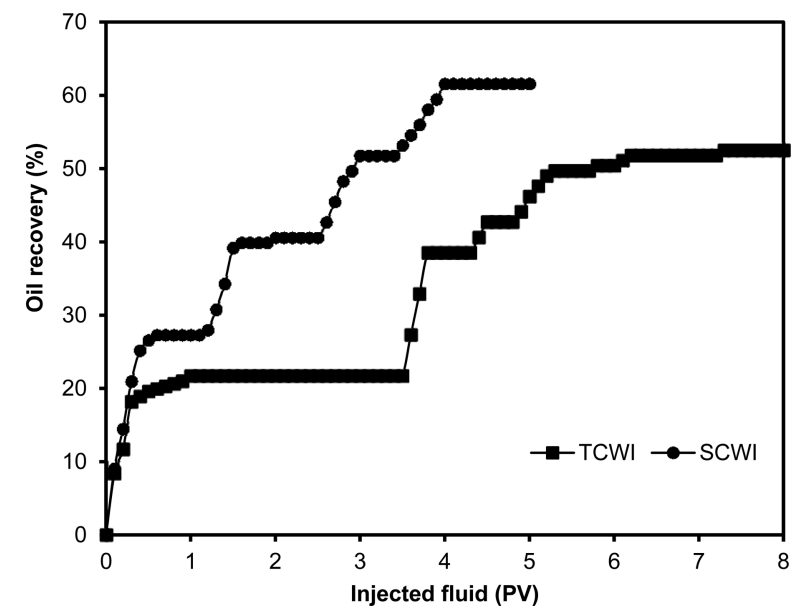

Figure 11. Oil recovery of SCWI and TCWI.

PV of injected CW was implemented after conducting 3 PV of conventional WF. And, SCWI was continued as much as $5 \mathrm{PV}$ with $\mathrm{CW}$ injected to the core. All the flooding experiments were conducted at $80{ }^{\circ} \mathrm{C}$ and 1000 psi.

As shown in Figure 11, oil recovery revealed similar trend with increasing the injected fluid. Oil recovery increased stagewise with CWI, regardless of being secondary or tertiary oil recovery method. For both SCWI and TCWI, oil recovery increased and then it reached a plateau and remained unchanged with further increasing PV. Again, after a plateau period, oil recovery increased to a maximum value and remained unchanged with further increasing the PV. This scenario continued for both SCWI and TCWI where the maximum oil recovery of $61.63 \%$ and $52.58 \%$ was achieved under SCWI and TCWI, respectively.

Experimental results showed that CWI is more efficient than the conventional WF. Several mechanisms are behind this improvement by CWI. The main mechanisms contributing to the additional recovery in CWI was found to be IFT reduction between oil and $\mathrm{CW}$ and oil swelling. Continuous $\mathrm{CO}_{2}$ mass transfer into oil phase, cause the trapped oil after water flooding to swell and reconnect. Thus, oil displacement and recovery increased as the results of CWI. Moreover, oil recovery could be due to wettability alteration to a more favorable condition, i.e., water wet condition, which resulted in improving the oil recovery. Another observation form core flood experiments was that SCWI is more efficient than the TCWI. This is due to the fact that TCWI took place after conventional WF, where some fraction of original oil in place was already produced. Thus, a lower amount of oil was there to be produced through TCWI.

Mosavat and Torabi $^{48}$ performed a micro-optical analysis of carbonated water injection in irregular and heterogeneous oil wet pore geometry system. Their micromodel observation revealed that, micromodel wettability is changed from oil wet to water wet with continues injection of CW. They found that CWI is capable of recovering an extra $3.1 \%$ of original oil in place. They also concluded that the extent of this recovery improvement can be correlated to $\mathrm{CO}_{2}$ solubility and mass transfer rate, which takes place in during CWI. In another study by Shakiba et al., ${ }^{42}$ effectiveness of SCWI and TCWI in improving the oil recovery in a coreflood system was investigated. They also concluded that $\mathrm{CW}$ injection is more beneficial that the conventional WF, however, SCWI found to be more efficient than the TCWI. They also concluded that oil swelling and viscosity reduction, which takes place during CW injection is the main mechanism responsible for improving the oil recovery by CWI as compared to conventional WF. An additional oil recovery of $40.54 \%$ and $56.74 \%$ was reported during tertiary and secondary carbonated water injection compared to conventional WF by the authors. In another study by Seyyedi and Sohrabi, ${ }^{63}$ the effectiveness of CWI in improving the oil recovery in carbonate and sandstone rocks was investigated. They also found that oil recovery is significantly increased with CWI compared to conventional WF. They concluded that viscosity reduction by oil swelling, IFT reduction between oil and brine, changes in wettability and mineral dissolution are the main mechanisms behind oil recovery increments with CWI. They also concluded that wettability alteration by $\mathrm{CW}$ injection is stronger in in carbonate rocks as compared to sandstone rocks.

\section{CONCLUSION}

This study investigated the effectiveness of CWI into an Iranian carbonate oil reservoir core samples for the purposes of improving oil recovery. $\mathrm{CO}_{2}$ solubility in formation brine and seawater was determined. IFT of different samples of carbonated brines and oil was determined. The following conclusions could be extracted from the studies performed:

1. $\mathrm{CO}_{2}$ solubility is increased with increasing pressure and decreasing temperature. On the other hand, $\mathrm{CO}_{2}$ 
solubility was higher in seawater compared to formation brine, which is due to lower salinity of seawater.

2. The presence of $\mathrm{CO}_{2}$ on IFT of brine and oil was found to be positive. The IFT of carbonated brine and oil was lower that than the IFT of normal brine and oil.

3. Increasing pressure had significant influence on IFT of carbonated brine and oil. The minimum IFT between carbonated brine and oil was achieved with 2500 psi, while the maximum value was achieved with 1000 psi.

4. IFT of carbonated brine and oil affected by temperature where the higher the temperature, the lower the IFT.

5. IFT of carbonated brine and oil decreased with increasing time, regardless of temperatures and pressures applied. $\mathrm{CO}_{2}$ absorption along the carbonated water and oil interface is promoted with time, which thus reduces IFT between carbonated brine and oil.

6. IFT was influenced by the brine nature as well. In all experiments, a lower value of IFT was resulted for CSW and oil compared to $\mathrm{CFB}$ and oil, which was due to lower salinity of seawater and higher $\mathrm{CO}_{2}$ solubility in seawater compared to formation brine.

7. CWI into carbonate cores found to be very promising in improving the oil recovery compared to conventional WF. In addition, SCWI was more effective than the TCWI because more oil was available in place for recovery. Maximum oil recoveries of $21.75 \%$, 61.63\%, and $52.58 \%$ was achieved with conventional WF, SCWI, and TCWI, respectively. IFT reduction and oil swelling were found to be the main mechanisms for improving oil recovery during CWI.

\section{AUTHOR INFORMATION}

\section{Corresponding Authors}

*Tel.: +(98) 9173145175. Fax: +(98) 7143311172. E-mail: honarvar.bzn@gmail.com (B.H.).

*Tel.: +(98) 9177057166. Fax: +(98) 7143311172. E-mail: amin.azhdarpour@miau.ac.ir (A.A.).

\section{ORCID 1}

Amin Azdarpour: 0000-0001-7826-2025

Notes

The authors declare no competing financial interest.

\section{ACKNOWLEDGMENTS}

The authors would like to gratefully acknowledge and appreciate the Department of Petroleum Engineering, Faculty of Engineering, Marvdasht Islamic Azad University, Marvdasht, 73711-13119, Iran, for the provision of the laboratory facilities necessary for completing this work.

\section{REFERENCES}

(1) EIA (United States Energy Information Administration). Annual Energy Review 2011. http://www.eia.gov/aer (accessed 06.02.13).

(2) Lam, V.; Li, G.; Song, C.; Chen, J.; Fairbridge, C.; Hui, R.; Zhang, J. A review of electrochemical desulfurization technologies for fossil fuels. Fuel Process. Technol. 2012, 98, 30-38.

(3) Sathre, R. Comparing the heat of combustion of fossil fuels to the heat accumulated by their lifecycle greenhouse gases. Fuel 2014, 115, 674-677.

(4) Mohr, S. H.; Wang, J.; Ellem, G.; Ward, J.; Giurco, D. Projection of world fossil fuels by country. Fuel 2015, 141, 120-135.

(5) Cao, M.; Gu, Y. Oil recovery mechanisms and asphaltene precipitation phenomenon in immiscible and miscible $\mathrm{CO}_{2}$ flooding processes. Fuel 2013, 109, 157-166.
(6) RezaeiDoust, A.; Puntervold, T.; Strand, S.; Austad, T. Smart Water as Wettability Modifier in Carbonate and Sandstone: A Discussion of Similarities/Differences in the Chemical Mechanisms. Energy Fuels 2009, 23 (9), 4479-4485.

(7) Li, Z.; Gu, Y. Soaking effect on miscible $\mathrm{CO}_{2}$ flooding in a tight sandstone formation. Fuel 2014, 134, 659-668.

(8) Yang, D.; Song, C.; Zhang, J.; Zhang, G.; Ji, Y.; Gao, J. Performance evaluation of injectivity for water-alternating- $\mathrm{CO}_{2}$ processes in tight oil formations. Fuel 2015, 139, 292-300.

(9) Kamari, A.; Arabloo, M.; Shokrollahi, A.; Gharagheizi, F.; Mohammadi, A. H. Rapid method to estimate the minimum miscibility pressure (MMP) in live reservoir oil systems during $\mathrm{CO}_{2}$ flooding. Fuel 2015, 153, 310-319.

(10) Fathi, S.; Austad, T.; Strand, S. Smart Water as a Wettability Modifier in Chalk: The Effect of Salinity and Ionic Composition. Energy Fuels 2010, 24 (4), 2514-2519.

(11) Fathi, S.; Austad, T.; Strand, S. Water-Based Enhanced Oil Recovery (EOR) by "Smart Water": Optimal Ionic Composition for EOR in Carbonates. Energy Fuels 2011, 25 (11), 5173-5179.

(12) Lau, L. C.; Lee, K. T.; Mohamed, A. R. Global warming mitigation and renewable energy policy development from the Kyoto Protocol to the Copenhagen Accord-A comment. Renewable Sustainable Energy Rev. 2012, 16, 5280-5284.

(13) Akorede, M. F.; Hizam, H.; Ab Kadir, M. Z. A.; Aris, I.; Buba, S. $D$. Mitigating the anthropogenic global warming in the electric power industry. Renewable Sustainable Energy Rev. 2012, 16, 2747-2761.

(14) Azdarpour, A.; Asadullah, M.; Junin, R.; Manan, M.; Hamidi, H.; Mohammadian, E. Direct carbonation of red gypsum to produce solid carbonates. Fuel Process. Technol. 2014, 126, 429-434.

(15) Azdarpour, A.; Asadullah, M.; Mohammadian, E.; Junin, R.; Hamidi, H.; Manan, M.; Daud, A. R. Mineral carbonation of red gypsum via $\mathrm{pH}$-swing process: Effect of $\mathrm{CO}_{2}$ pressure on the efficiency and products characteristics. Chem. Eng. J. 2015, 264, 425-436.

(16) Azdarpour, A.; Asadullah, M.; Mohammadian, E.; Hamidi, H.; Junin, R.; Karaei, M. A review on carbon dioxide mineral carbonation through pH-swing process. Chem. Eng. J. 2015, 279, 615-630.

(17) Strand, S.; Austad, T.; Puntervold, T.; Høgnesen, E. J.; Olsen, M.; Barstad, S. M. F. Smart Water for Oil Recovery from Fractured Limestone: A Preliminary Study. Energy Fuels 2008, 22 (5), 31263133.

(18) Olajire, A. A. A review of mineral carbonation technology in sequestration of $\mathrm{CO}_{2}$. J. Pet. Sci. Eng. 2013, 109, 364-392.

(19) Li-ping, H.; Ping-ping, S.; Xin-wei, L.; Qi-Chao, G.; Chengsheng, W.; Fangfang, L. Study on $\mathrm{CO}_{2}$ EOR and its geological sequestration potential in oil field around Yulin city. J. Pet. Sci. Eng. 2015, 134, 199-204.

(20) Heller, J. P.; Dandge, D. K.; Card, R. J.; Donaruma, L. G. Direct Thickeners for Mobility Control of $\mathrm{CO}_{2}$ Floods. SPEJ, Soc. Pet. Eng. J. 1985, 25, 679-686.

(21) Christensen, J. R.; Stenby, E. H.; Skauge, A. review of WAG field experience. SPE Reservoir Evaluation \& Engineering 2001, 4, 97-106.

(22) Talebian, S. H.; Rahim, M. P.; Tan, I. M.; Pacelli, L. J. Foam assisted $\mathrm{CO}_{2}$-EOR; concepts, challenges and applications. In Proceedings SPE Enhanced Oil Recovery Conference, Kuala Lumpur, Malaysia, July 2-4, 2013.

(23) Laochamroonvorapongse, R.; Kabir, C. S.; Lake, L. W. Performance assessment of miscible and immiscible water-alternating gas floods with simple tools. J. Pet. Sci. Eng. 2014, 122, 18-30.

(24) Han, L.; Gu, Y. Optimization of Miscible $\mathrm{CO}_{2}$ WaterAlternating-Gas Injection in the Bakken Formation. Energy Fuels 2014, 28, 6811-6819.

(25) Shariatpanahi, S. F.; Hopkins, P.; Aksulu, H.; Strand, S.; Puntervold, T.; Austad, T. Water Based EOR by Wettability Alteration in Dolomite. Energy Fuels 2016, 30 (1), 180-187.

(26) Suicmez, V. S.; Piri, M.; Blunt, M. J. Pore-scale Simulation of Water Alternate Gas Injection. Transp. Porous Media 2007, 66, 259286. 
(27) RezaeiDoust, A.; Puntervold, T.; Austad, T. Chemical Verification of the EOR Mechanism by Using Low Saline/SmartWater in Sandstone. Energy Fuels 2011, 25 (5), 2151-2162.

(28) Lashkarbolooki, M.; Ayatollahi, S.; Riazi, M. Effect of Salinity, Resin, and Asphaltene on the Surface Properties of Acidic Crude Oil/ Smart Water/Rock System. Energy Fuels 2014, 28 (11), 6820-6829.

(29) Lashkarbolooki, M.; Ayatollahi, S.; Riazi, M. Correction to Effect of Salinity, Resin, and Asphaltene on the Surface Properties of Acidic Crude Oil/Smart Water/Rock System. Energy Fuels 2015, 29 (7), $4665-4665$

(30) Bera, A.; Ojha, K.; Mandal, A. Synergistic Effect of Mixed Surfactant Systems on Foam Behavior and Surface Tension. J. Surfactants Deterg. 2013, 16 (4), 621-630.

(31) Kumar, S.; Mandal, A. Studies on interfacial behavior and wettability change phenomena by ionic and nonionic surfactants in presence of alkalis and salt for enhanced oil recovery. Appl. Surf. Sci. 2016, 372, 42-51.

(32) Kumar, S.; Panigrahi, P.; Saw, R. K.; Mandal, A. Interfacial Interaction of Cationic Surfactants and Its Effect on Wettability Alteration of Oil-Wet Carbonate Rock. Energy Fuels 2016, 30, 28462857.

(33) Sohrabi, M.; Riazi, M.; Jamiolahmady, M.; Ireland, S.; Brown, C. Carbonated water injection for oil recovery and $\mathrm{CO}_{2}$ storage. In Proceedings of the Sustainable Energy UK Conference: Meeting the Science and Engineering Challenge, Oxford, UK, 2008.

(34) Sohrabi, M.; Riazi, M.; Jamiolahmady, M.; Ireland, S.; Brown, C. Carbonated water injection (CWI) studies. In Proceedings of the 29th Annual Workshop \& Symposium, IEA Collaborative Project on Enhanced Oil Recovery, Beijing, China, 2008.

(35) Sohrabi, M.; Riazi, M.; Jamiolahmady, M.; Ireland, S.; Brown, C. Mechanisms of oil recovery by carbonated water injection. In SCA Annual Meeting, 2009.

(36) Sohrabi, M.; Riazi, M.; Jamiolahmady, M.; Idah Kechut, N. I.; Ireland, S.; Robertson, G. Carbonated water injection (CWI)-A productive way of using $\mathrm{CO}_{2}$ for oil recovery and $\mathrm{CO}_{2}$ storage. Energy Procedia 2011, 4, 2192-2199.

(37) Sohrabi, M.; Kechut, N. I.; Riazi, M.; Jamiolahmady, M.; Ireland, S.; Robertson, G. Safe storage of $\mathrm{CO}_{2}$ together with improved oil recovery by $\mathrm{CO}_{2}$-enriched water injection. Chemical Engineering research and Design 2011, 89, 1865-1872.

(38) Shariatpanahi, S. F.; Strand, S.; Austad, T. Evaluation of WaterBased Enhanced Oil Recovery (EOR) by Wettability Alteration in a Low-Permeable Fractured Limestone Oil Reservoir. Energy Fuels 2010, 24 (11), 5997-6008.

(39) Riazi, M.; Jamiolahmady, M.; Sohrabi, M. Theoretical investigation of pore-scale mechanisms of carbonated water injection. J. Pet. Sci. Eng. 2011, 75, 312-326.

(40) Hasanvand, M. Z.; Ahmadi, M. A.; Shadizadeh, S. R.; Behbahani, R.; Feyzi, F. Geological storage of carbon dioxide by injection of carbonated water in an Iranian oil reservoir: A case study. J. Pet. Sci. Eng. 2013, 111, 170-177.

(41) Foroozesh, J.; Jamiolahmady, M.; Sohrabi, M. Mathematical modeling of carbonated water injection for $\mathrm{EOR}$ and $\mathrm{CO}_{2}$ storage with a focus on mass transfer kinetics. Fuel 2016, 174, 325-332.

(42) Shakiba, M.; Ayatollahi, S.; Riazi, M. Investigation of oil recovery and $\mathrm{CO}_{2}$ storage during secondary and tertiary injection of carbonated water in an Iranian carbonate oil reservoir. J. Pet. Sci. Eng. 2016, 137, 134-143.

(43) Mosavat, N.; Torabi, F. Performance of Secondary Carbonated Water Injection in Light Oil Systems. Ind. Eng. Chem. Res. 2014, 53, 1262-1273.

(44) Mosavat, N.; Torabi, F. Experimental evaluation of the performance of carbonated water injection (CWI) under various operating conditions in light oil systems. Fuel 2014, 123, 274-284.

(45) Alizadeh, A. H.; Khishvand, M.; Ioannidis, M. A.; Piri, M. Multiscale experimental study of carbonated water injection: An effective process for mobilization and recovery of trapped oil. Fuel 2014, 132, 219-235.
(46) Mosavat, N.; Torabi, F. Micro-optical analysis of carbonated water injection in irregular and heterogeneous pore geometry. Fuel 2016, 175, 191-201.

(47) Sohrabi, M.; Kechut, N. I.; Riazi, M.; Jamiolahmady, M.; Ireland, S.; Robertson, G. Coreflooding Studies to Investigate the Potential of Carbonated Water Injection as an Injection Strategy for Improved Oil Recovery and $\mathrm{CO}_{2}$ storage. Transp. Porous Media 2012, 91, 101-121.

(48) Mohammadian, E.; Hamidi, H.; Asadullah, M.; Azdarpour, A.; Motamedi, S.; Junin, R. Measurement of $\mathrm{CO}_{2}$ solubility in $\mathrm{NaCl}$ brine solutions at different temperatures and pressures using the potentiometric titration method. J. Chem. Eng. Data 2015, 60, 2042-2049.

(49) Shu, G.; Dong, M.; Chen, S.; Luo, P. Improvement of $\mathrm{CO}_{2}$ EOR performance in water-wet reservoirs by adding active carbonated water. J. Pet. Sci. Eng. 2014, 121, 142-148.

(50) Duan, Z. H.; Sun, R. An improved model calculating $\mathrm{CO}_{2}$ solubility in pure water and aqueous $\mathrm{NaCl}$ solutions from 273 to 533 $\mathrm{K}$ and from 0 to 2000 bar. Chem. Geol. 2003, 193, 257-271.

(51) Lee, L. L. A molecular theory of Setchenov's salting-out principle and applications in mixed-solvent electrolyte solutions. Fluid Phase Equilib. 1997, 131, 67-82.

(52) Nighswander, J. A.; Kalogerakis, N.; Mehrotra, A. K. Solubilities of carbon dioxide in water and $1 \mathrm{wt} \% \mathrm{NaCl}$ solutions at pressures up to $10 \mathrm{MPa}$ and temperatures from 80 to $200{ }^{\circ} \mathrm{C}$. J. Chem. Eng. Data $1989,34,355-360$.

(53) Zumdahl, S. S. Chemical Principles, 4th ed.; Houghton Mifflin Company: Boston, MA, 2002.

(54) Riazi, M.; Golkari, A. The influence of spreading coefficient on carbonated water alternating gas injection in a heavy crude oil. Fuel 2016, 178, 1-9.

(55) Dreybrodt, W.; Lauckner, J.; Zaihua, L.; Svensson, U.; Buhmann, D. The kinetics of the reaction $\mathrm{CO}_{2}+\mathrm{H}_{2} \mathrm{O} \rightarrow \mathrm{H}^{+}+$ $\mathrm{HCO}_{3}{ }^{-}$as one of the rate limiting steps for the dissolution of calcite in the system $\mathrm{H}_{2} \mathrm{O}-\mathrm{CO}_{2}-\mathrm{CaCO}_{3}$. Geochim. Cosmochim. Acta 1996, 60, 3375-3381.

(56) Yang, D.; Gu, Y. Interfacial Interactions between Crude Oil and $\mathrm{CO}_{2}$ under Reservoir Conditions. Pet. Sci. Technol. 2005, 23, 10991112.

(57) Myers, D. Surfaces I. Colloids; Wiley-VCH: New York, 1999.

(58) Moeini, F.; Hemmati-Sarapardeh, A.; Ghazanfari, M. H.; Masihi, M.; Ayatollahi, S. Towards mechanistic understanding of heavy crude oil/brine interfacial tension: the roles of salinity, temperature and pressure. Fluid Phase Equilib. 2014, 375, 191-200.

(59) De Silva, G. P. D.; Ranjith, P. G.; Perera, M. S. A. Geochemical aspects of $\mathrm{CO}_{2}$ sequestration in deep saline aquifers: A review. Fuel 2015, 155, 128-143.

(60) Fathinasab, M.; Ayatollahi, S. On the determination of $\mathrm{CO}_{2}-$ crude oil minimum miscibility pressure using genetic programming combined with constrained multivariable search methods. Fuel 2016, $173,180-188$.

(61) Mollaiy-Berneti, S. Determination of minimum miscibility pressure in $\mathrm{CO}_{2}$-IOR projects with the aid of hybrid neuro-fuzzy system. Fuel 2016, 180, 59-70.

(62) Yang, D.; Tontiwachwuthikul, P.; Gu, Y. Interfacial Interactions between Reservoir Brine and $\mathrm{CO}_{2}$ at High Pressures and Elevated Temperatures. Energy Fuels 2005, 19, 216-223.

(63) Seyyedi, M.; Sohrabi, M. Enhancing Water Imbibition Rate and Oil Recovery by Carbonated Water in Carbonate and Sandstone Rocks. Energy Fuels 2016, 30, 285-293. 